Libray Copy-Save

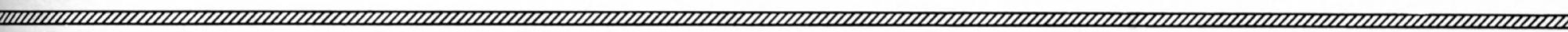

\title{
PREPRINTS
}

OF THE

\author{
STEWARD OBSERVATORY
}

THE UNIVERSITY OF ARIZONA

TUCSON, ARIZONA

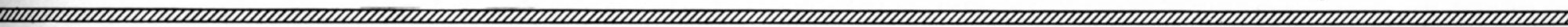

No. 12

LIGHT VARIATIONS OF THE SEYFERT GALAXY NGC 4151

W. S. FITCH

A. G. PACHOLCZYK

R. J. WEYMANN

SEPTEMBER, 1967 
LIGHT VARIATIONS OF THE SEYFERT GALAXY NGC 4151

by

W. S. Fitch

A. G. Pacholczyk

R. J. Weymann

September, 1967 


\section{LIGHT VARIATIONS OF THE SEYFERT GALAXY NGC 4151}

The discovery of strong infrared radiation from the nucleus of the Seyfert galaxy NGC 1068 (Pacholczyk and Wisniewski, 1967) strengthened the evidence for a possible relationship between Seyfert galaxies and quasistellar sources, discussed some time ago by Burbidge, Burbidge and Sandage (1965) and by Shklovskii (1965). A few other Seyfert galaxies (among them NGC 4151) have since been detected in the infrared (Pacholczyk and Weymann, 1967).

The similarity of the radio, infrared and ultraviolet continua between some of the nuclei of Seyfert galaxies and some of the quasistellar sources led to the suggestion that Seyfert nuclei might show light variations. Since the quasar-1ike excess radiation in the Seyfert nuclei is the 1argest in the ultraviolet and in the far infrared, larger light variations were to be expected in these spectral regions (Pacholczyk and Wisniewski, 1967).

In the spring of 1967 the Seyfert galaxy NGC 4151 was measured photoelectrically in the U, B, V, and $\mathrm{K}$ passbands. The UBV measurements were carried out with the 36-inch reflector of the Steward Observatory at Kitt Peak using a standard single channel photometer and reduced using a computer program developed by one of us (W.S.F.). The infrared $\mathrm{K}$ measures were made with Johnson's JKL photometer (Johnson and Mitche11, 1962) attached to the 60-inch reflector of the Lunar and Planetary Laboratory at Mt. Lemmon.

The UBV measures were made with a 36" diaphragm on J.D. 2439599, 2439601, and with a 32" diaphragm thereafter, and the $\mathrm{K}$ measures utilized a 15" diaphragm. Observations on JD 2439648 were made with both a 32" and 44" diaphragm. Note however that an increase in brightness was observed despite the switch to a smaller diaphragm. 
In Table 1 are 1isted individual UBV measures on NGC 4151 and a comparison star situated $5^{\prime}$ from the nucleus at P.A. $150^{\circ}$, and it may be seen from these measures, tied directly to the standard system each night, that there are no significant variations in the comparison star during the observing season and that the mean error of a single observation is 0.04 , 0.02 , and $0.02 \mathrm{mag}$ in $\mathrm{V}, \mathrm{B}$, and $\mathrm{U}$, respectively.

In Table 2 we give the average magnitude of NGC 4151 on each night, where the UBV measures have been corrected differentially with respect to the comparison star. On JD 2439631 only the $U$ magnitude is given, because a bright moon made the $B$ and $V$ measures uncertain whereas the mean error in $\mathrm{U}$ appears to be $0.03 \mathrm{mag}$ on this night.

We believe that real changes in brightness occur during the course of one night, with an observed range of about 1 mag in $K, 0.15$ mag in $U$, and $0.09 \mathrm{mag}$ in $\mathrm{B}$. In Table 2 it is seen that over the period of the observations the galaxy increased in brightness by about $0.45 \mathrm{mag}$ in $\mathrm{U}, 0.25 \mathrm{mag}$ in $B$, and $0.20 \mathrm{mag}$ in $\mathrm{V}$. The last three $\mathrm{K}$ measures utilized a comparison star of $\mathrm{K}=8.5 \mathrm{mag}, 7^{\prime}$ distant at P.A. $280^{\circ}$, as a check. At maximum light the probable error of a flux measure in $\mathrm{K}$ is about 25\%, however on JD 39619 the galaxy was just at the limit of detectability, so we cannot make a good error estimate for that measure but we are convinced that NGC 4151 was significantly fainter then.

The suspicion that the amplitude of the variations of flux depends upon the spectral region and ought to be larger in the region where the quasar-1ike component makes the largest contribution seems to be confirmed. 
We are aware of only two other UBV measures of NGC 4151. The first is by de Vaucouleurs (1959) whose value, measured in the 1957-58 season with a 24" diaphragm is $\mathrm{V}=11.78, \mathrm{~B}-\mathrm{V}=0.66, \mathrm{U}-\mathrm{B}=-0.31(\mathrm{U}=12.13)$. The 2nd set was obtained on JD 2439505.0 and JD 2439509.0 by W. Z. Wisniewski with the L.P.L. 28" reflector using a 27" diaphragm. His values are, for the first night $V=11.46, B-V=0.59, U-B=-0.50(U=11.55)$ and on the second night $\mathrm{V}=11.42, \mathrm{~B}-\mathrm{V}=0.57, \mathrm{U}-\mathrm{B}=-0.60(\mathrm{U}=11.39)$. These observations support the reality of the variations.

In connection with the apparent variability of the nonstellar component of the nucleus we note that two trailed spectra of the nucleus of NGC 4151 which we have inspected (Morgan 1967, Sargent 1967) show apparent differences in the strength of the underlying stellar absorption lines. Since the plates were taken with different instruments one cannot be certain how much of these apparent differences are real, but a reasonable interpretation is that the stellar component is drowned out as the nonstellar component increases.

The Seyfert galaxy 1068 is being currently observed for variability in the U, B, V; $\mathrm{K}$ and millimeter spectral regions.

We wish to thank Dr. H. L. Johnson for permission to use his instrumentation. The kind assistance of $\mathrm{Dr}$. W. Z. Wisniewski in observing, of Messrs. R. I. Mitchell and J. C. Geary in reducing the data and Mr. W. Fogarty in preparing the diagram is gratefully acknowledged.

$$
\begin{aligned}
& \text { W. S. Fitch } \\
& \text { A. G. Pacholczyk } \\
& \text { R. J. Weymann }
\end{aligned}
$$




\section{REFERENCES}

Burbidge, E. M., and Burbidge, G. R. and Sandage, A. R. 1965, in Quasistellar Sources and Gravitational Collapse, ed. I. Robinson, A. E. Schild, and E. L. Schucking (Chicago: University of Chicago Press).

Johnson, H. L., and Mitche11, R. I. 1962, Com. Lunar and Planetary Lab., No. 14 .

Pacholczyk, A. G., and Weymann, R. J. (to be published).

Pacholczyk, A. G., and Wisniewski, W. Z. 1967, Ap. J., 147, 394.

Sandage, A. R. 1964, Ap. J., 139, 416.

Shklovskii, I. S. 1965, Astr. Zh., 42, 893.

Vaucouleurs, G. de. 1959, Lowell Obs. Bull., Vol. 4, No. 97. 
TABLE 1

INDIVIDUAL UBV MAGNITUDES OF NGC 4151

Comparison Star

\begin{tabular}{|c|c|c|c|c|}
\hline $\begin{array}{l}\text { Hel. J.D. } \\
2439000+\end{array}$ & V & B & $\mathrm{U}$ & $\begin{array}{l}\text { Hel. J.D } \\
2439000+\end{array}$ \\
\hline 99.737 & 9.758 & 10.445 & 10.343 & $\begin{array}{l}599.755 \\
599.760\end{array}$ \\
\hline $\begin{array}{l}599.778 \\
601.760\end{array}$ & $\begin{array}{l}9.803 \\
9.854\end{array}$ & $\begin{array}{l}10.359 \\
10.423\end{array}$ & $\begin{array}{l}10.414 \\
10.409\end{array}$ & $\begin{array}{l}599.764 \\
601.769 \\
601.772\end{array}$ \\
\hline $\begin{array}{l}601.784 \\
601.833\end{array}$ & $\begin{array}{l}9.848 \\
9.852\end{array}$ & $\begin{array}{l}10.431 \\
10.429\end{array}$ & $\begin{array}{l}10.399 \\
10.425\end{array}$ & $\begin{array}{l}601.776 \\
601.842 \\
601.845\end{array}$ \\
\hline $\begin{array}{l}601.857 \\
648.678 \\
648.700 \\
648.714 \\
648.737 \\
648.762 \\
648.774 \\
648.785\end{array}$ & $\begin{array}{l}9.687 \\
9.849 \\
9.842 \\
9.830 \\
9.832 \\
9.830 \\
9.826 \\
9.799\end{array}$ & $\begin{array}{l}10.435 \\
10.432 \\
10.422 \\
10.423 \\
10.424 \\
10.409 \\
10.430 \\
10.393\end{array}$ & $\begin{array}{l}10.360 \\
10.387 \\
10.404 \\
10.401 \\
10.393 \\
10.393 \\
10.424 \\
10.406\end{array}$ & $\begin{array}{l}601.850 \\
648.703 \\
648.717 \\
648.758 \\
648.768 \\
648.778 \\
648.706 \\
648.722\end{array}$ \\
\hline $\begin{array}{l}655.675 \\
655.692\end{array}$ & $\begin{array}{l}9.829 \\
9.831\end{array}$ & $\begin{array}{l}10.411 \\
10.373\end{array}$ & $\begin{array}{l}10.401 \\
10.402\end{array}$ & $\begin{array}{l}655.684 \\
655.687\end{array}$ \\
\hline Mean & $\begin{array}{r}9.818 \\
\pm .011\end{array}$ & $\begin{array}{r}10.416 \\
\pm .006\end{array}$ & $\begin{array}{r}10.397 \\
\pm .006\end{array}$ & . \\
\hline
\end{tabular}

NGC 4151

B

U
Diaphragm Size (seconds of arc)

$\begin{array}{llll}11.335 & 11.958 & 11.480 & 36 \\ 11.353 & 11.968 & 11.435 & 36 \\ 11.332 & 11.967 & 11.424 & 36 \\ 11.332 & 11.907 & 11.310 & 36 \\ 11.341 & 11.896 & 11.279 & 36 \\ 11.367 & 11.899 & 11.286 & 36 \\ 11.309 & 11.865 & 11.263 & 36 \\ 11.306 & 11.874 & 11.294 & 36 \\ 11.319 & 11.877 & 11.279 & 36 \\ 11.209 & 11.713 & 10.945 & 32 \\ 11.213 & 11.720 & 10.963 & 32 \\ 11.280 & 11.725 & 11.022 & 32 \\ 11.270 & 11.733 & 11.040 & 32 \\ 11.293 & 11.804 & 11.089 & 32 \\ 11.033 & 11.573 & 10.844 & 44 \\ 11.035 & 11.586 & 10.851 & 44 \\ 11.048 & 11.587 & 10.914 & 44 \\ 11.203 & 11.691 & 11.009 & 32 \\ 11.187 & 11.695 & 10.991 & 32\end{array}$

36 36 36 36 36 36 36 36 36 32 32 32 32 32 44 44 44 32
32 
TABLE 2

MEAN UBVK MAGNITUDES OF NGC 4151

$\begin{array}{ccccc}\text { J.D. } & \text { U } & \text { B } & \text { V } & \text { K } \\ 2439000+ & & & & \\ & & & & \\ 530.0 & & & & 8.4 \\ 598.9 & & & & 9.4 \\ 599.8 & 11.46 & 11.98 & 11.38 & \\ 601.8 & 11.28 & 11.87 & 11.34 & \\ 619.9 & & & & 10.2 \\ 623.7 & 11.20 & 11.86 & 11.26 & \\ 631.8 & 11.14 & & & \\ 642.7 & 10.89 & 11.63 & 11.13 & \\ 648.7 & 11.01 & 11.74 & 11.24 & \\ 655.7 & 11.00 & 11.72 & 11.18 & 8.7 \\ 656.7 & & & & 8.5 \\ 657.7 & & & & 8.5\end{array}$




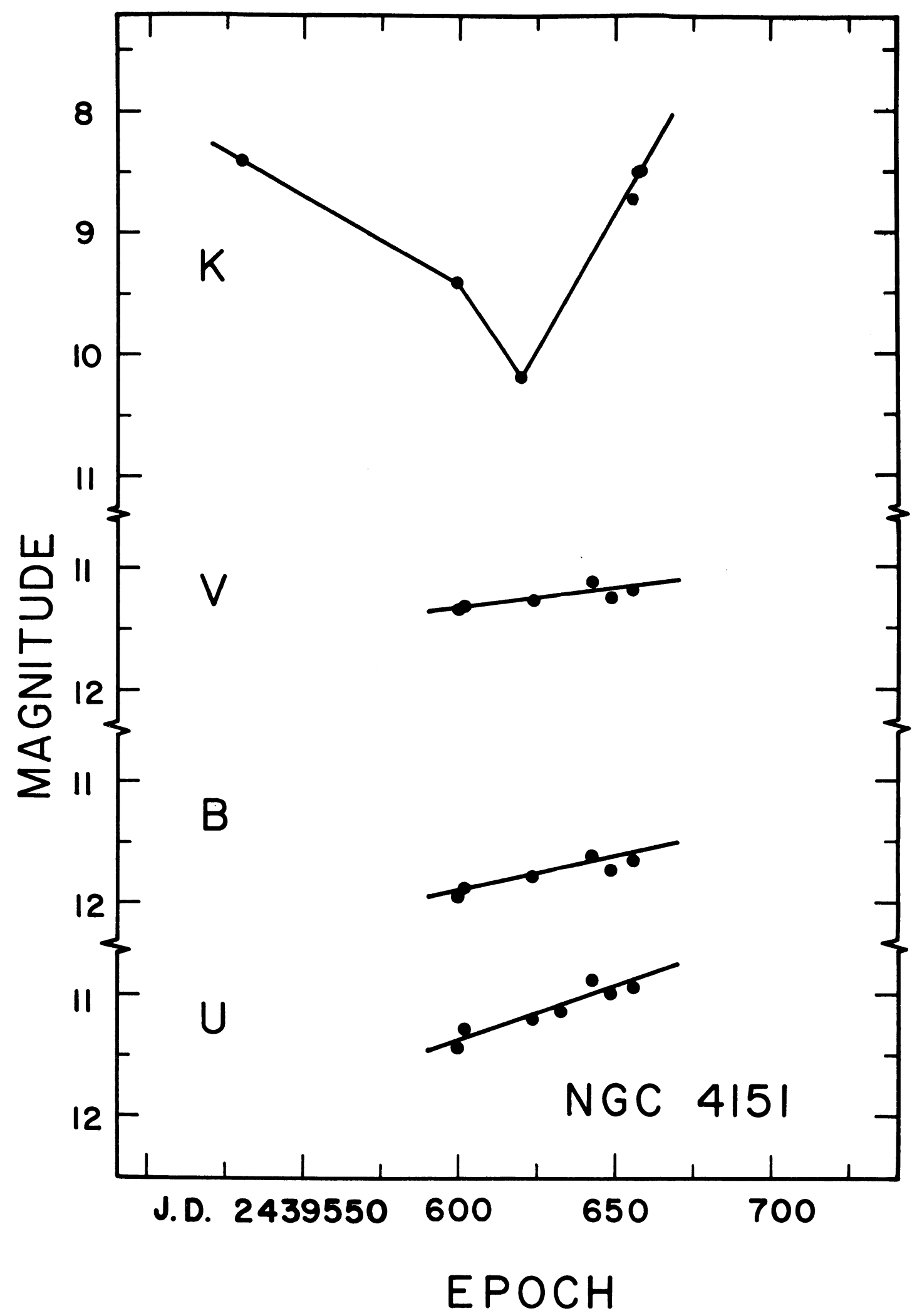

Fig. 1. Light variations of the Seyfert Galaxy NGC 4151 in the U, B, V and $\mathrm{K}$ spectral regions. 